\title{
SANDSTONE PORE ASPECT RATIO SPECTRA FROM DIRECT OBSERVATIONS AND VELOCITY INVERSION
}

\author{
by \\ D.R. Burns, C.H. Cheng and R.H. Wilkens \\ Earth Resources Laboratory \\ Department of Earth, Atmospheric, and Planetary Sciences \\ Massachusetts Institute of Technology \\ Cambridge, MA 02139
}

\begin{abstract}
Measurements of pore shapes from Scanning Electron Microscope (SEM) images for three sandstone samples (the Navajo Sandstone, the Weber Sandstone, and the Kayenta Sandstone) are compared to the aspect ratio spectra obtained from inverting laboratory velocity versus pressure data using the method of Cheng and Toksöz (1979). The results indicate that the inversion method is in very good agreement with the observations at high aspect ratios $(\alpha>0.01)$. At low aspect ratios the agreement is very good for the clean Navajo Sandstone sample, but poor for the Weber and Kayenta samples which contain clay. The Navajo sample is composed chiefly of quartz with significant pressure dissolution apparent along grain contacts resulting in smooth, flat cracks between grains. The Weber and Kayenta samples have rougher crack surfaces as well as tapered pore edges, indicating that asperities and non-elliptical pore shapes may result in an over estimation of low aspect ratio cracks by velocity inversion. The presence of degraded feldspars may also play a role.
\end{abstract}

\section{INTRODUCTION}

For the past thirty years the effect of cracks and pore structure on various rock properties has been the subject of intense study. This effort has been especially fruitful in explaining the behavior of rocks as a function of pressure due to the closing of cracks (Walsh, 1965). Recent studies have continued this line of investigation by attempting to describe the pore structure in some quantitative way. Simmons et al. (1974) introduced the the differential strain analysis (DSA) technique which relates high precision static strain measurements to the closure pressures of penny shaped cracks as described by Walsh (1965). Feves and Simmons (1976) applied the DSA method to the Westerly Granite to estimate the aspect ratios of stress induced cracks. Cheng and Toksöz (1979) estimated pore structure by calculating a spectrum of pore aspect ratios $(\alpha)$ from the inversion of laboratory velocity measurements at various pressures. Their procedure was based on calculated crack closure rates, and the velocity modelling of two phase media developed by Kuster and Toksöz (1974). More recently, Simmons et al. (1982, 1983) have employed Scanning Electron Microscope (SEM) images and point counting techniques to quantify pore space in an effort to explain rock behavior and the role of clays. Pore structure estimates from both the SEM and inversion methods have been used successfully to predict rock properties. Toksöz et al. (1976) used the inversion spectra to model the in-situ velocity of rocks with varying pore fluids. 
Brace (1977) used the crack spectra from both methods to estimate permeability using the Carman-Kozeny capillary model. Wilkens et al. (1984) used SEM porosity studies to derive an effective aspect ratio spectrum of a suite of sandstones which successfully explained the velocity behavior of a wide range of samples. All of these studies indicate that a knowledge of pore structure provides a means of predicting many rock properties.

Aithough the velocity inversion spectrum has been successful in predicting rock behavior in several instances, a comparison of this spectrum with the actual pore distribution from SEM images would provide a measure of how well the inversion technique represents the pore structure. Cheng and Toksöz (1979) compared the inversion spectrum for Westerly Granite to that obtained by Hadley (1976) from SEM images. The agreement was quite good down to aspect ratios of about 0.001 , but smaller values were beyond the resolution of the SEM images. Kowallis et al. (1982) compared crack aspect ratio spectra from the SEM and inversion methods for Icelandic basalt. They concluded that the two spectra were similar in a small region of overlap, but that the resolution limits of the two methods were significantly different. The inversion method can only be expected to resolve between aspect ratios that close within the pressure range of the lab measurements (1-2kbars). Using the penny shaped crack expressions from Walsh (1965), and assuming quartz moduli, a pressure of 1 kbar would close cracks with an aspect ratio of about 0.001 .

SEM images, on the other hand, are more reliable at the high aspect ratio end. Hadley (1976) and Kowallis et al. (1982) both had SEM resolution limits of about $0.03 \mu \mathrm{m}$ for crack width measurements due to the conductive coating on the samples. This limit, together with the fact that most crack lengths were on the order of the average crystal size ( roughly $10 \mu \mathrm{m}$ ), restricted the aspect ratio measurements to values greater than about 0.003 .

To date there have been no comparisons between the two techniques for clastic rocks. Sandstones present several problems since the porosity (in most cases) is primarily contained in large, irregular, high aspect ratio pores. Such pores are difficult to characterize and measure on SEM images and also fall in the region of poorest resolution for the velocity inversion method. This study will compare SEM and velocity inversion spectra for three sandstones of varying porosity: Weber $(9.5 \%)$, Navajo (11.8\%), and Kayenta (22.2\%).

\section{PROBLEM FORMULATION}

SEM

SEM images using the backscattered electron mode were acquired for all 3 samples from crack sections as described in Simmons and Richter (1976) and used in Simmons et al. (1982, 1983). A conductive carbon coating was applied to all samples to avoid surface charge build up. Magnification ranges from 20 to $7700 \mathrm{x}$ were used which allowed measurement of crack widths down to $0.2 \mu \mathrm{m}$. Pore measurements were performed on images at $112 x$ which provided adequate resolution and a fairly representative area ( about $1 \mathrm{~mm}^{2}$ ). Crack widths were measured at higher magnifications and applied to cracks visible on the $112 x$ images. There were very few cracks observable at high magnification which could not be identified on the primary image (112x) and these were ignored due to the extremely small pore volume represented. Because pore shapes in sandstones can be large and Irregular, a set of criteria was developed to allow consistent measurements to be 
obtained. Pores were categorized into four groups following the terminology used by Simmons et al. (1982, 1983): intergranular, intergranular/tabular, connective, and micro (clay filling). These groupings were based on the following set of criteria:

intergranular:

high aspect ratio pores situated between

3 or more grains

intergranular/tabular:

tabular pores connecting intergranular pores;

situated between 2 grains

connective;

cracks of low aspect ratio, comprised of grain contacts and intragrain cracks

micro:

the pores contained in clay filling material

exceptions:

(i) no intergranular/tabular pore can have its major axis perpendicular to a grain face.

(ii) no pore is subdivided if the pore width changes by less than $50 \%$ over the length of the pore.

(iii) pores with major axis direction changes of more than 30 degrees are subdivided into multiple pores.

The effect of clays on the elastic properties of porous rocks is the subject of much discussion. Wilkens et al. (1984), based on a study 20 sandstone samples with varying clay content, contend that the clay filling is non-supportive and, therefore, the shape of the pore containing the clay will affect the elastic properties of the rock, but the effect of the clay is limited to reducing the porosity of the sample. If, on the other hand, the clay is coupled to the sandstone framework, then the shape of the individual pores within the clay zones would affect the elastic properties of the rock. In order to simplify the characterization of the pore volume contained in the clay zones, the total area containing clay on the SEM image was measured. Then, based on the results of Simmons et al. $(1982,1983)$ and Wilkens et al. (1984), the clay filled zones were assumed to have a porosity of $50 \%$ and the pores were assumed to have an aspect ratio of 0.2 . Since the results of this study are only concerned with the total pore volume contained in pores of given aspect ratios, the entire pore volume of these clay zones was represented by a single 'equivalent pore' of aspect ratio 0.2 .

For each sample the pores were traced on mylar and characterized by the criteria just given. Each pore was measured in the following way. Pore length was taken as the longest straight line which could be drawn totally within the pore. Pore width was measured perpendicular to the length chord and taken as the mean width of the pore. Crack lengths were measured from the same micrograph but crack 
widths were based on higher magnification images.

Pore volume was calculated by using the area average approximation (Hadley, 1976). This scheme compared favorably with the conventional point counting technique for one of the samples (Navajo Sandstone, see next section). It is assumed throughout this paper that the samples are isotropic, that the pore distribution is completely random, and that the measurement of pore shapes in two dimensions is somehow representative of the actual three dimensional structure. None of these assumptions is strictly true for any rock; however the results appear to be sufficiently consistent to Justify the approach taken. In addition, the complicated nature of the sandstone pore structure necessitated the use of a somewhat subjective set of criteria for analysis. However, because the great majority of pore volume is contained in high aspect ratio pores $(>0.01)$, the criteria are not too critical for measuring aspect ratios. The study of pore widths and lengths would be much more sensitive to these criteria.

\section{Velocity Inversion}

Velocity data for the 3 samples was previousiy collected by Coyner (1934). The inversion procedure of Cheng and Toksöz (1979) was used to generate the aspect ratio spectrum which provided the best fit to the velocity versus pressure data, with the added constraint that the crack closing rate is controlled by the static rather than the dynamic compressibility.

\section{RESULTS}

In this section the pore aspect ratio spectrum of. each sample based on SEM image analysis and velocity inversion is presented.

\section{Navajo Sandstone}

The Navajo Sandstone is a fine grained and well sorted quartz rich sandstone which contains essentially no clay filling. The sample has a measured porosity of $11.8 \%$ (Coyner, 1984). A low magnification SEM image (Figure 1) shows that the porosity is not homogeneously distributed on this small scale. In order to obtain a representative area, two micrographs were used in the analysis of this sample representing the high and low porosity zones seen in Figure 1 (Figures 2 and 3 ). The area of each image was $0.9375 \mathrm{~mm}^{2}$. The characterized pores are shown in Figures 4 through 7 . The calculated porosity from the area average method was $7.2 \%$ for the low porosity image (Figure 2) and $13.8 \%$ for the high porosity image (Figure 3 ). The overall calculated pcrosity for both images was $10.6 \%$. This value was checked by point counting (1518 points) over both images which yielded $10.9 \%$ porosity. A total of 486 pores were measured from the two images with a range of aspect ratios of 1.0 to 0.0011 . The spectra obtained from each of the two images separately are shown in Figure 8a. Although the low porosity image contained fewer very high aspect ratio pores $(>0.1)$ and more lower aspect ratio pores $(<0.1)$, in general the agreement between the two spectra is very good. This comparison supports the assumption of homogeneity of the pore distribution since a very similar spectrum can be obtained even in zones differing by a factor of 2 in porosity. The pore characterizations from both images were combined to give an overall SEM aspect ratio spectrum which is shown, together with the velocity inversion spectrum in Figure $8 b$. 
The agreement between the SEM pore aspect ratio spectrum and the spectrum obtained from velocity inversion is very good over the entire range of aspect ratios. Since the SEM data represents a continuum of aspect ratios, the pore volume contained in a range of aspect ratios is summed to give the histogram shown in Figure $8 \mathrm{~b}$ (in this and subsequent figures each bar of the histogram contains all aspect ratios less than or equal to the left edge value and greater than the right edge value). Initially, the spectrum obtained from the SEM images for each sample will be presented with the same aspect ratio groupings for easy comparison. A slightly different grouping of the SEM data for this sample (dashed line in Figure $8 \mathrm{~b}$ ) reflects the fact that the inversion method has lumped all pore volume for aspect ratios between 0.1 and 0.005 into the single value at 0.1 .

\section{Weber Sandstone}

The Weber Sandstone is a very fine grained arkosic sandstone containing a moderate amount of clay and some calcite. Figure 9 shows the sample at low magnification. A representative area near the center of Figure 9 was chosen for analysis (Figure 10). Figures 11 and 12 show the pore characterization. A total of 386 pores were measured. The calculated porosity (area average) was $9.4 \%$ versus a measured porosity of $9.5 \%$ (Coyner, 1984). The range of aspect ratios measured was 1.0 through 0.0018 . Pore aspect ratio spectra from the SEM analysis and velocity inversion are shown in Figure 13. The agreement between the two spectra is very good at the high aspect ratio end $(\alpha>0.005)$ but poor at the low aspect ratio end. The inversion method predicts that $26 \%$ of the pore volume is contained in pores with an aspect ratio of 0.1 . This value is much higher than that predicted for the Navajo Sandstone ( $5-12 \%$ depending on the grouping, Figure $8 \mathrm{~b}$ ) and is in close agreement with the observed spectrum. Most of the observed difference between the Weber Sandstone and Navajo Sandstone for $\alpha$ between 0.2 and 0.02 can be attributed to the clay present in the Weber sample. The clay content of the Weber Sandstone is $2.1 \%$ of the area examined (Figure 12) containing $1.05 \%$ porosity or $11 \%$ of the total porosity which is included in the aspect ratio of 0.2 . In addition, there is a greater density of grain to grain contacts and intragrain cracks present in the Weber sample (Figure 12).

\section{Kayenta Sandstone}

The Kayenta Sandstone is a fine to medium grained poorly consolidated arkose which is clay rich (Figure 14). A single micrograph was used for analysis and is shown in Figure 15. The calculated porosity of this sample based on the area average method was $17.9 \%$ versus a measured porosity of $22.2 \%$. A total of 246 pores were measured (Figures 16 and 17) encompassing an aspect ratio range of 1.0 -0.00167 . The spectra obtained from the two methods are given in Figure 18 (the SEM data is given by the solid line and the inversion data is given by the stars). The agreement between the two methods is poor at all aspect ratios. The image analyzed for this sample (Figure 15) had a clay content of $3 \%(1.5 \%$ porosity or about $3 \%$ of the total porosity). A closer examination of the low magnification image (Figure 14) indicates that the clay content of the overall sample is probably close to $10 \%$. It seems, then, that the analysis carried out for this sample under-represented the clay filling material by about a factor 3 . In order to see if this under-sampling was responsible for the poor agreement between the two spectra, the clay content of the SEM data was increased by a factor of 3 (all other pore data were left unchanged). The calculated porosity for this case increased to about $21 \%$, very close to the measured value for the sample, and the agreement between the two spectra is much 
improved at the high aspect ratios (dashed line in Figure 18), although the agreement is still relatively poor at the low aspect ratio end.

Wilkens et al. (1984) in their discussion of the effect of clays on the velocity of porous rocks indicated that the clay content reduces the porosity of the rock, but doesn't reduce the framework pore space. In effect, they argue that the clay is decoupled from the grain framework of the rock and that the velocity of the rock is still controlled by the framework pore space. In order to test this hypothesis, the Kayenta Sandstone velocity data was inverted a second time with the same aspect ratio distribution but with a $5 \%$ increase in porosity (representing the approximate non-void volume of the clay filling). The results (triangles in Figure 18) show better agreement at the high aspect ratios with the actual SEM observations (solid line in Figure 18). Although the agreement at low aspect ratios is sightly better, the match is still fairly poor. This one example lends some support to the Wilkens et al. (1984) clay model, although much additional work is needed to fully evaluate the hypothesis.

\section{DISCUSSION AND CONCLUSIONS}

There is good agreement at high aspect ratios between the spectra obtained from the analysis of SEM images and velocity inversion for the Navajo and Weber Sandstones. The Kayenta Sandstone showed poor agreement, but this can be attributed in part to the non-representative area used for the analysis which severely under sampled the clay content. The agreement at low aspect ratios was good for the Navajo Sandstone, but quite poor for the Weber and Kayenta Sandstones, both of which had a fair amount of clay. There is undoubtedly some error involved in SEM measurements for fine cracks with low aspect ratios, but this does not explain the discrepencies between the apparent agreement for the clean sample and the lack of agreement for the two samples with clay. A close examination of the SEM images for the 3 samples indicates that the grain to grain contacts are somewhat different for the Navajo sample when compared to the Weber and Kayenta samples. The Navajo Sandstone is predominantly composed of quartz with some feldspar. The feldspar is very fresh with almost no degradation visible. The grain contacts between the quartz grains have almost all been cemented by the reprecipitation of quartz through pressure dissolution. The result is that the grain contacts appear as fine cracks with few asperities. The Weber and Kayenta samples, on the other hand, have less quartz dissolution along grain boundaries and the feldspars are degraded, especially in the Kayenta Sandstone. As a result, the Navajo Sandstone grain contacts appear as flat cracks while the Weber and Kayenta samples appear to have fairly rough crack surfaces. In addition, the Weber and Kayenta samples have more tapering along the pore edges than the Navajo sample. All of these observed features could affect the elastic behavior of the rocks. Asperities along crack surfaces may alter the crack stiffnesses, while tapered pore edges would result in non-elliptical pore shapes (Mavko and Nur, 1978) which would have somewhat less stiffness than an elliptical crack of the same aspect ratio ( a non-elliptical pore, then, would behave like a thinner elliptical pore, or some combination of thinner elliptical pores). Degraded feldspar grains could also alter the elastic behavior of the sample. In general, then, the lack of agreement at low aspect ratios for the Weber and Kayenta samples may be due to the presence of degraded feldspars or the fact that there has been less quartz dissolution along grain boundaries to smooth out and flatten the grain contacts, resulting in an overestimation of the low aspect ratio cracks from the velocity inversion. For the Navajo Sandstone sample, the velocity inversion method does not appear to be 
overestimating the pore volume in these low aspect ratio pores, probably due to the fresh grains and smooth, flat grain contacts.

In general, the resuits indicate that the velocity inversion method of Cheng and Toksöz (1979) is representative of the pore structure of sandstones at high aspect ratios as quantified by 2 dimensional SEM images. An empirical result of this study is that the great majority of sandstone pore volume is contained in high aspect ratio pores ( $>0.01$ ) and that the clay zone porosity is an important source of pore volume in the 0.2 aspect ratio range.

\section{ACXNOWLEDGEMENTS}

The authors would like to thank Tom Wissler for the use of his crack sections and his help in obtaining the SEM images used in this study. D.R. Burns was partially supported by a Phillips Petroleum Fellowship.

\section{REFERENCES}

Brace, W.F., 1977, Permeability from resistivity and pore shape: J. Geophys. Res., v.82, p.3343-3349.

Cheng, C.H. and Toksöz, M.N., 1979, Inversion of seismic velocities for the pore aspect ratio spectrum of a rock: J. Geophys. Res.; v.84, p.7533-7543.

Coyner, K.B., 1984, Effects of stress, pore pressure, and pore fluids on bulk strain, velocity, and permeability in rocks: Ph.D. thesis, MIT, Cambridge,MA.

Feves, M. and Simmons, G., 1976, Effects of stress on cracks in westerly granite: BSSA, v.66, p.1755-1765.

Hadley, K., 1976, Comparison of calculated and observed crack densities and seismic velocities in westerly granite: J. Geophys. Res., v.81, p.3484-3494.

Kowallis, B.J., Roeloffs, E.A., and Wang, H.F., 1982, Microcrack studies of the Iceland research drilling project: J. Geophys. Res., v.87, p.6650-66.56.

Kuster, G.T. and Toksöz, M.N., 1974, Velocity and attenuation of seismic waves in two phase media, part 1-theoretical formulations: Geophysics, v.39, p.587-606.

Mavko, G. and Nur, A., 1978, The effect of nonelliptical cracks on the compressibility of rocks: J. Geophys. Res., v.83, p.4459-4468.

Simmons, G. and Richter, D., 1976, Microcracks in rocks, in The physics and chemistry of minerals and rocks, edited by R.J.G. Sterns: Interscience, New York, p.105137.

Simmons, G., Siegfried, R.W., and Feves, M., 1974, Differential strain analysis: a new method for examining cracks in rocks: J. Geophys. Res., v.79, p.4383-4335.

Simmons, G., Wilkens, R., Caruso, L., Wissler, T., and Miller, F., 1982, Physical properties and microstructures of a set of sandstones: annual report to the 
Schlumberger-Doll Research Center.

Simmons, G., Wilkens, R., Caruso, L, Wissier, T., and Miller, F., 1983, Physical properties and microstructures of a set of sandstones: annual report to the Schlumberger-Doll Research Center.

Toksöz, M.N., Cheng, C.H., and Timur, A., 1976, Velocities of seismic waves in porous rocks: Geophysics,v.41, p.621-645.

Walsh, J.B., 1965, The effect of cracks on the compressibility of rock: J. Geophys. Res., v.70, p.381-389.

Wilkens, R.H., Simmons, G., Wissler, T., and Caruso, L., 1984, The physical properties of a set of sandstones, lli: the effects of fine grained pore filling on compressional wave velocity: submitted to Geophysics. 


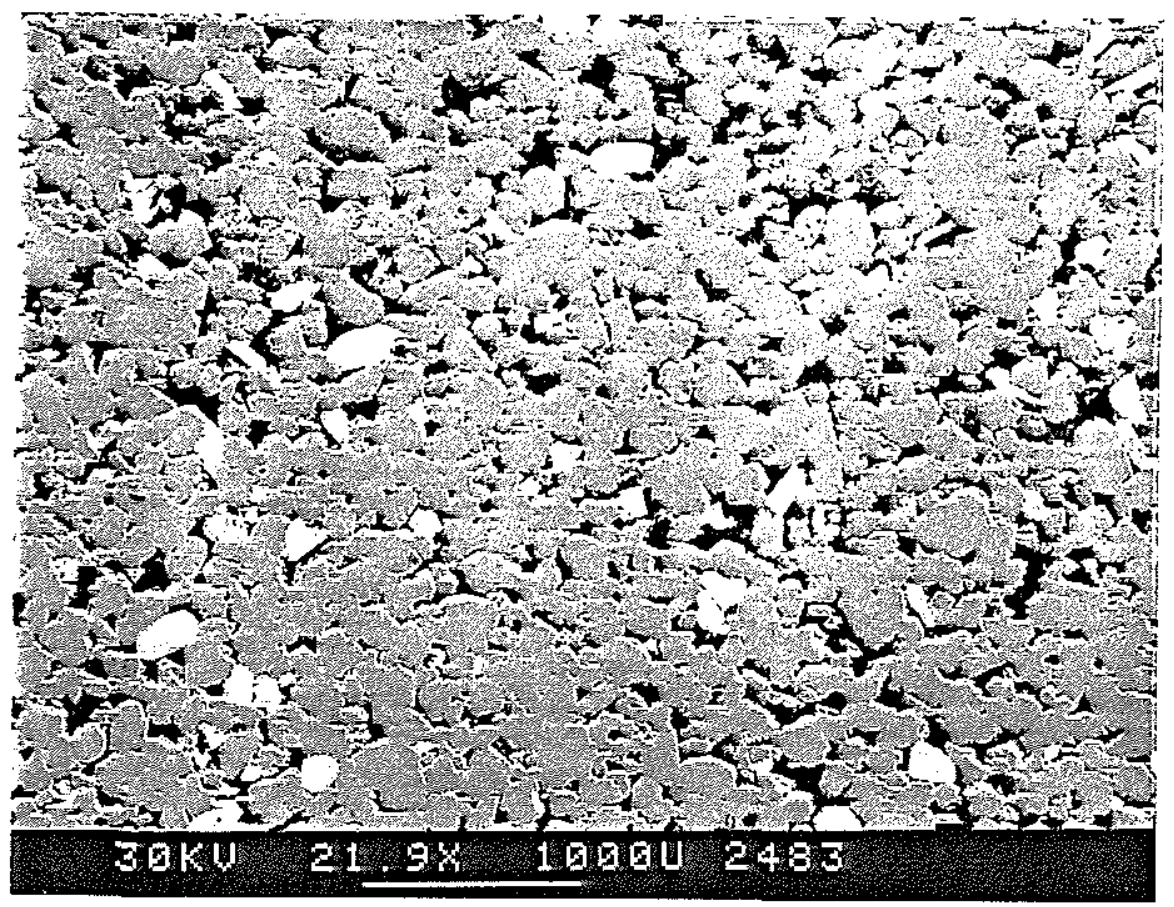

Figure 1: Low magnification (21.9x) SEM image of Navajo Sandstone 


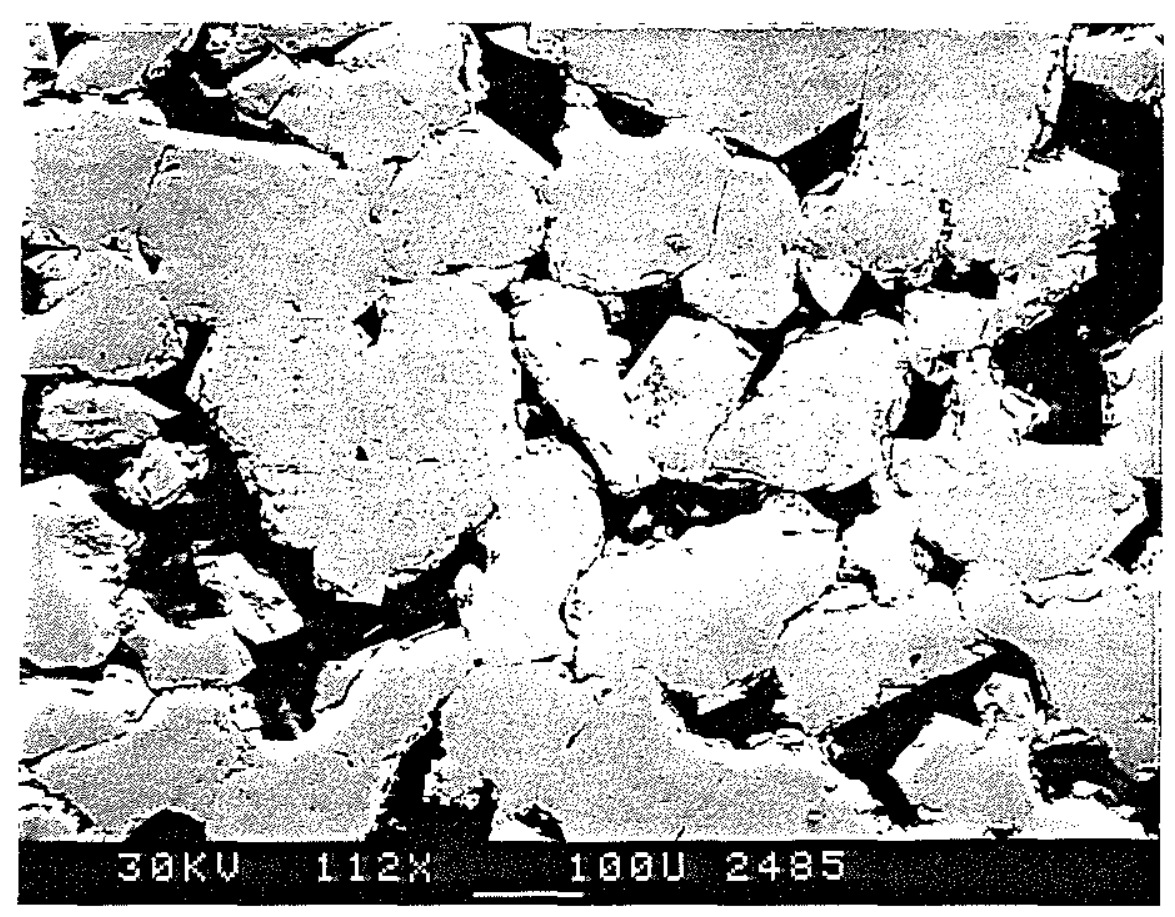

Figure 2: One of two primary SEM images used in pore characterization for Navajo Sandstone (112x). This image is representive of the high porosity zones of the sample.

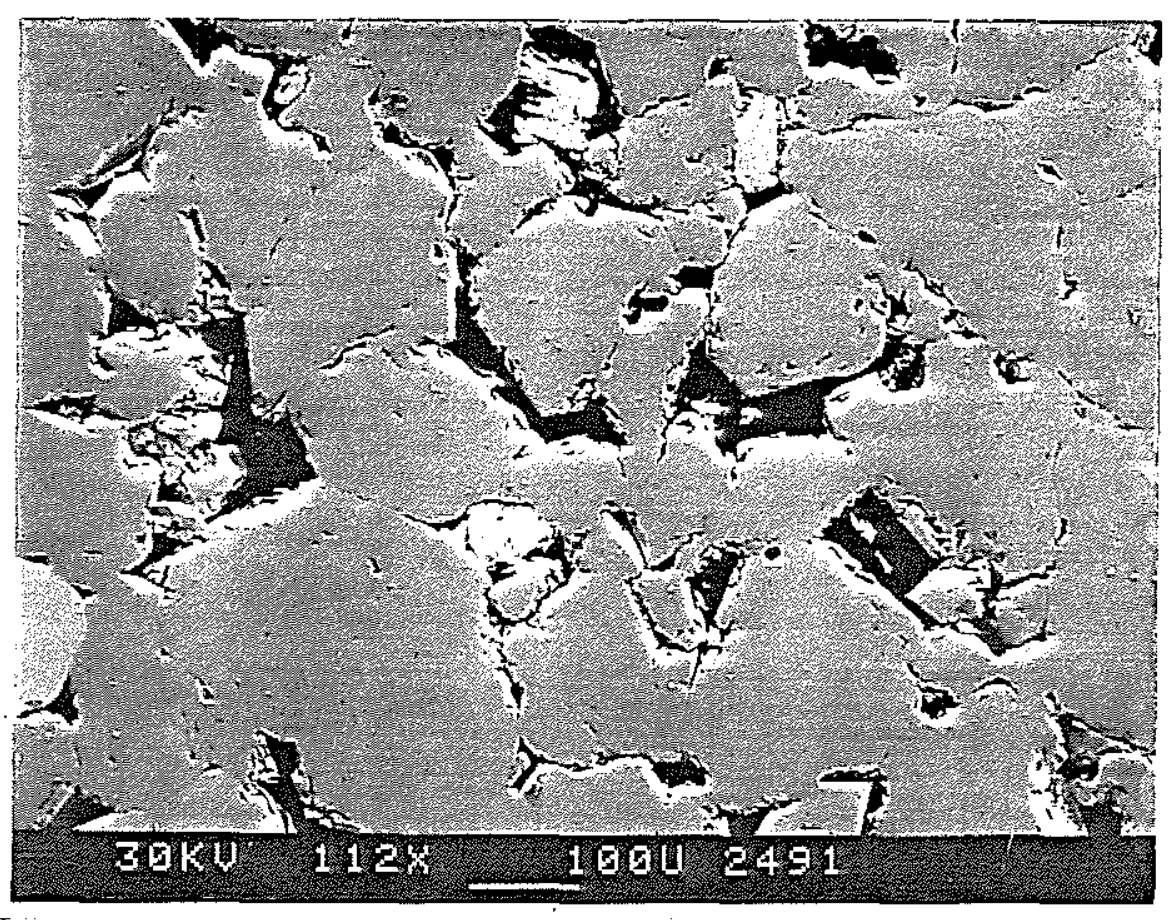

Figure 3: The second primary image used in characterizing the pores of the Navajo Sandstone (112x). This image is representive of the low porosity zones of the sample. 


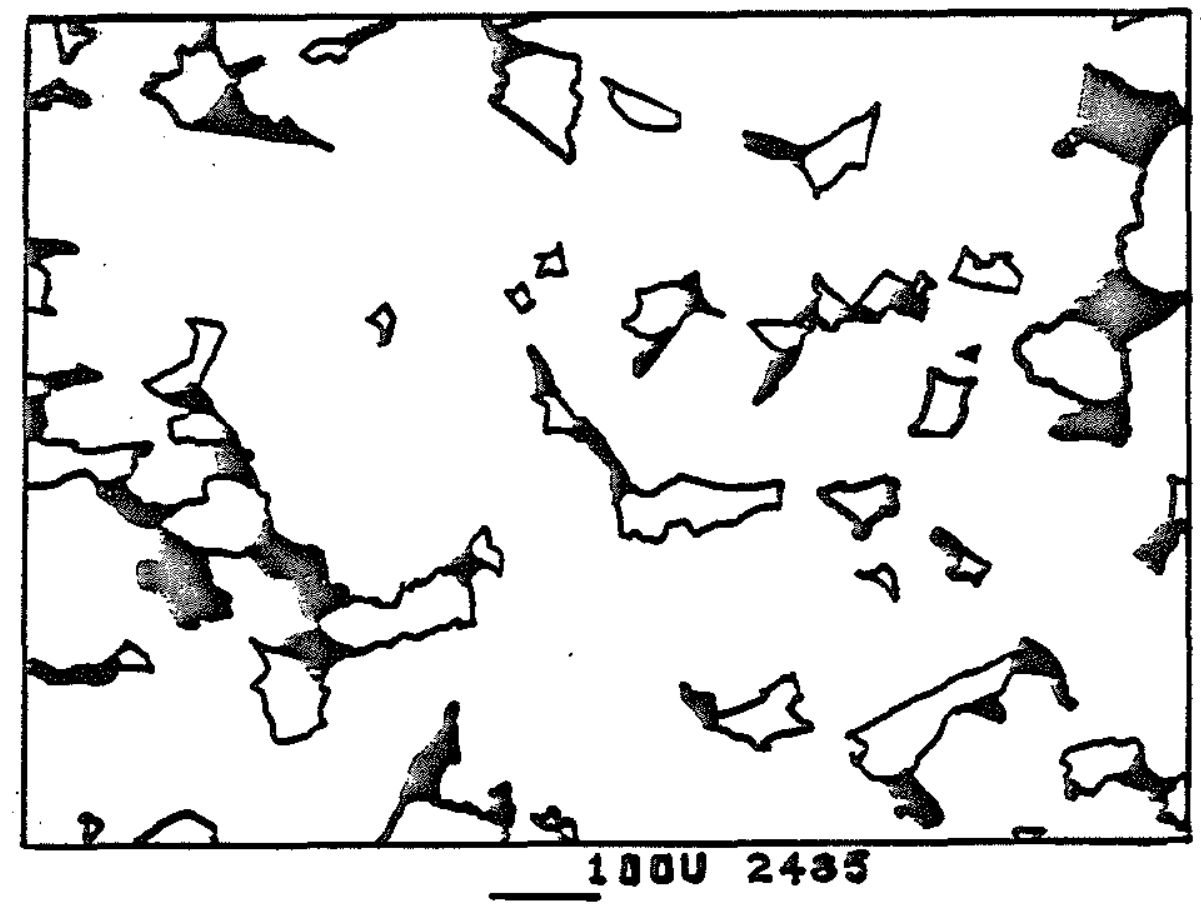

Figure 4: Intergranular (open) and intergranular/tabular (shaded) pores from the high porosity image (fig.2) for the Navajo Sandstone.

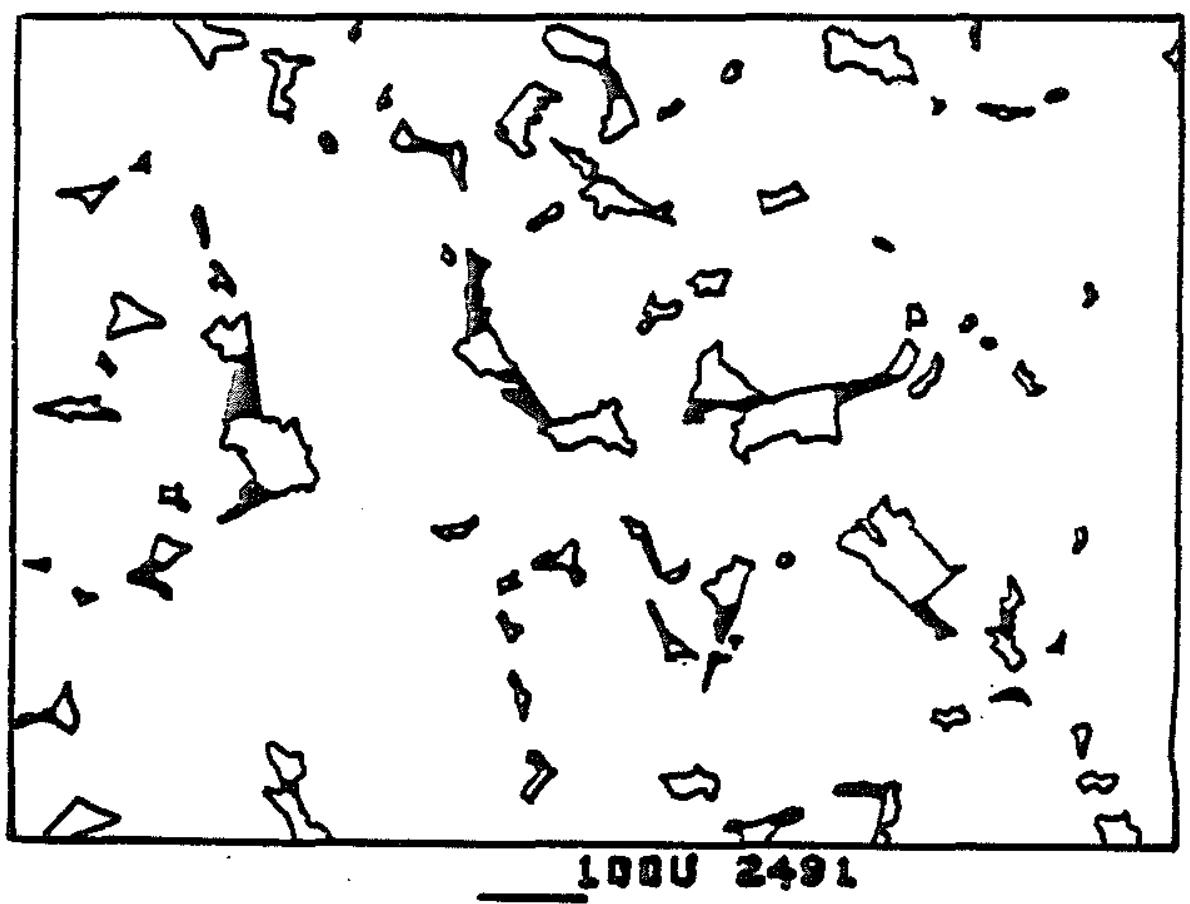

Figure 5: Intergranular (open) and intergranular/tabular (shaded) pores from the low porosity image (fig.3) for the Navajo Sandstone. 


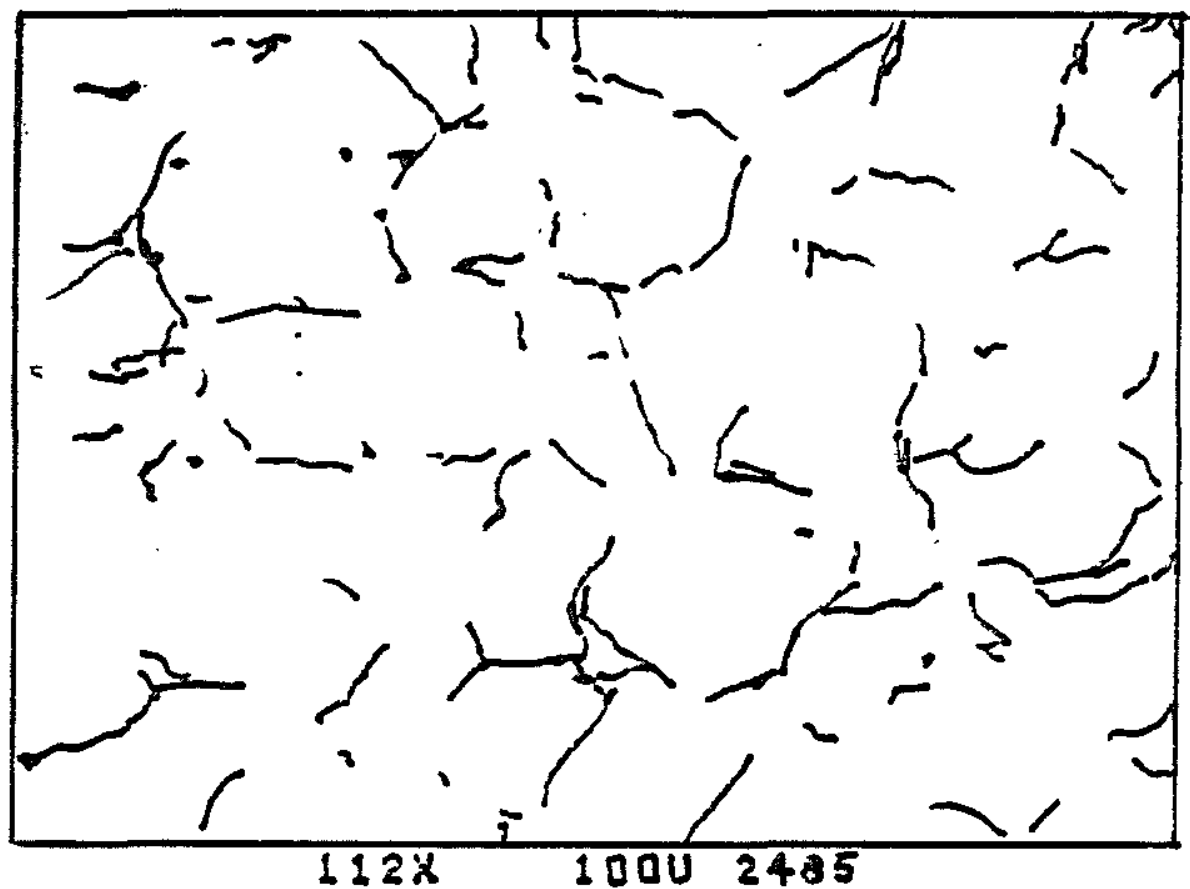

Figure 6: Connective pores from the high porosity image (fig.2) for the Navajo Sandstone.

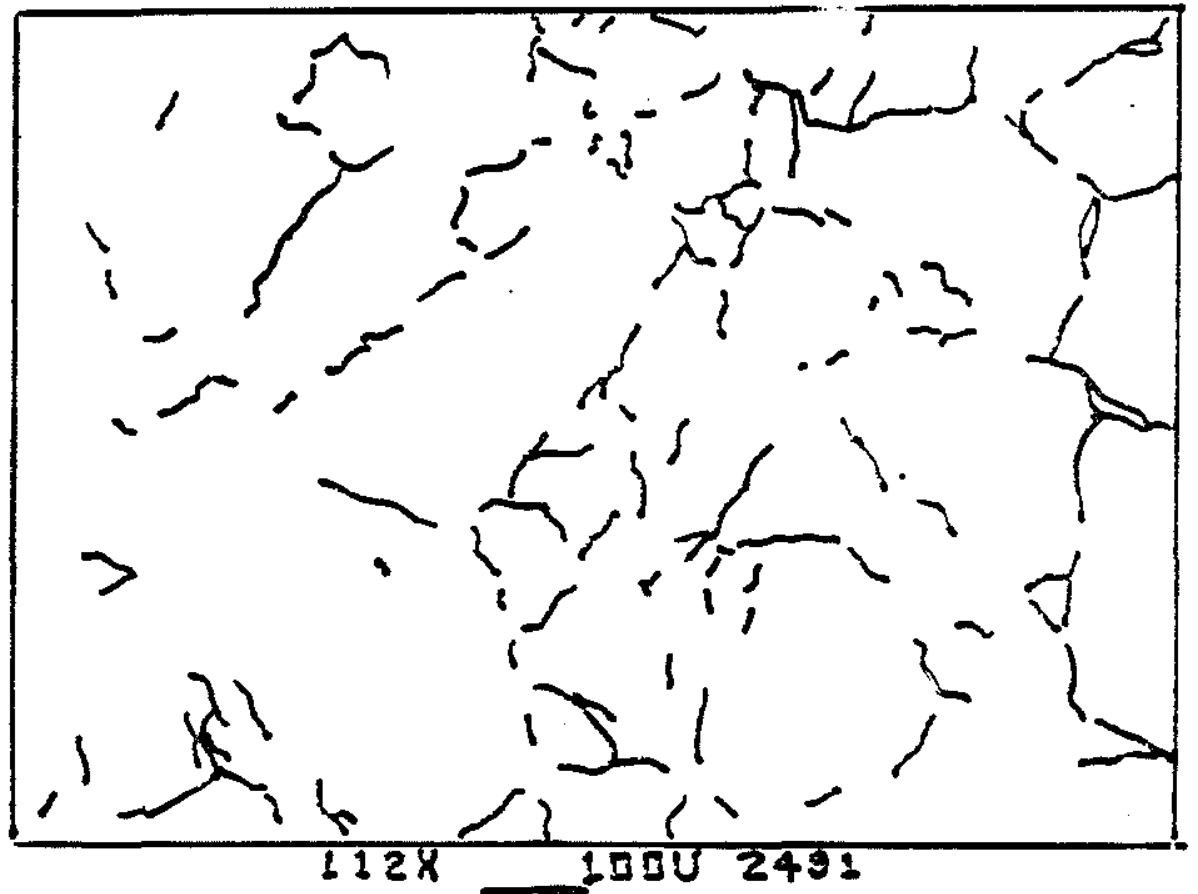

Figure 7: Connective pores from the low porosity image (fig.3) for the Navajo Sandstone. 


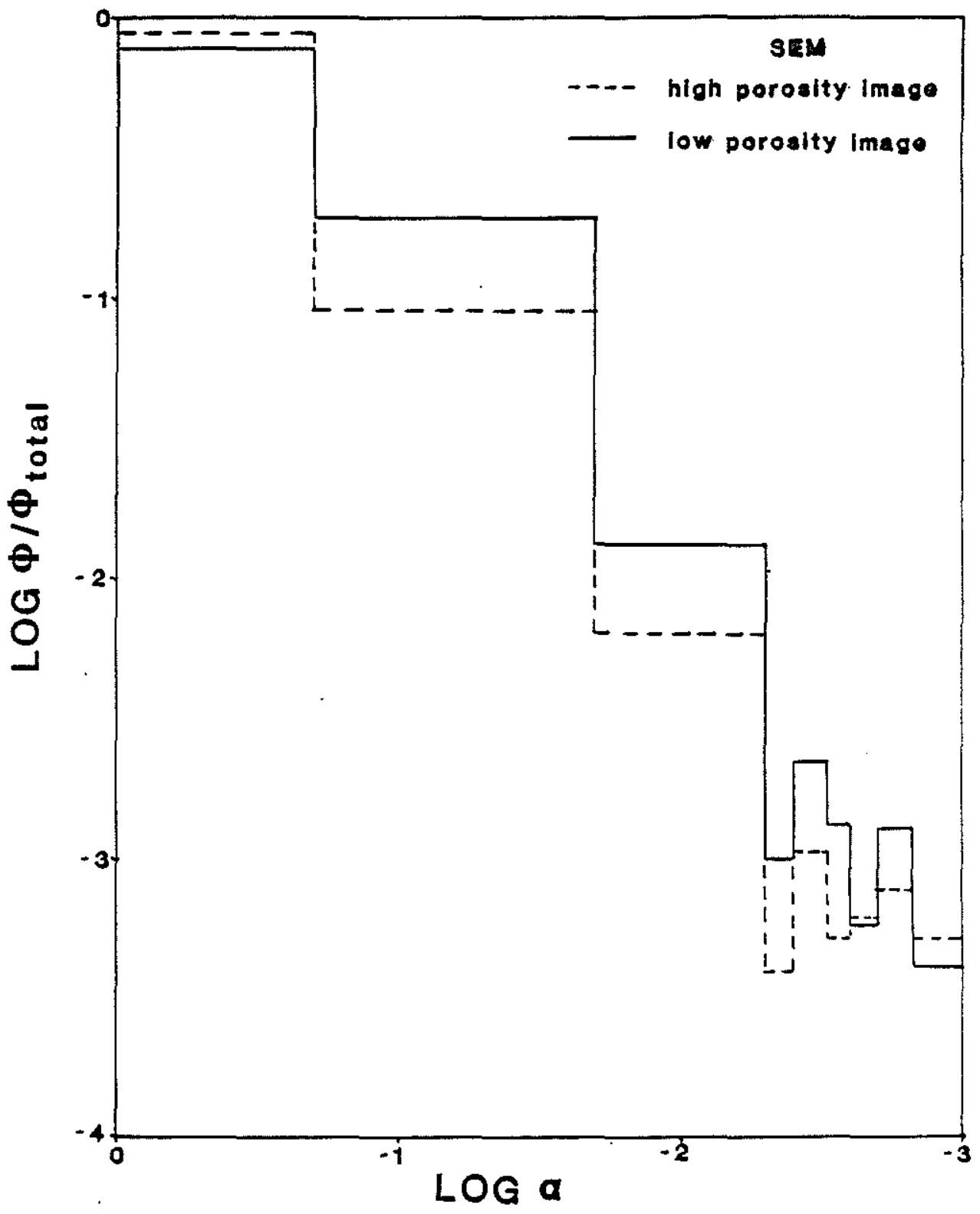

Figure 8a: Aspect ratio spectra for the Navajo Sandstone from the SEM measurements on the high and low porosity images. 


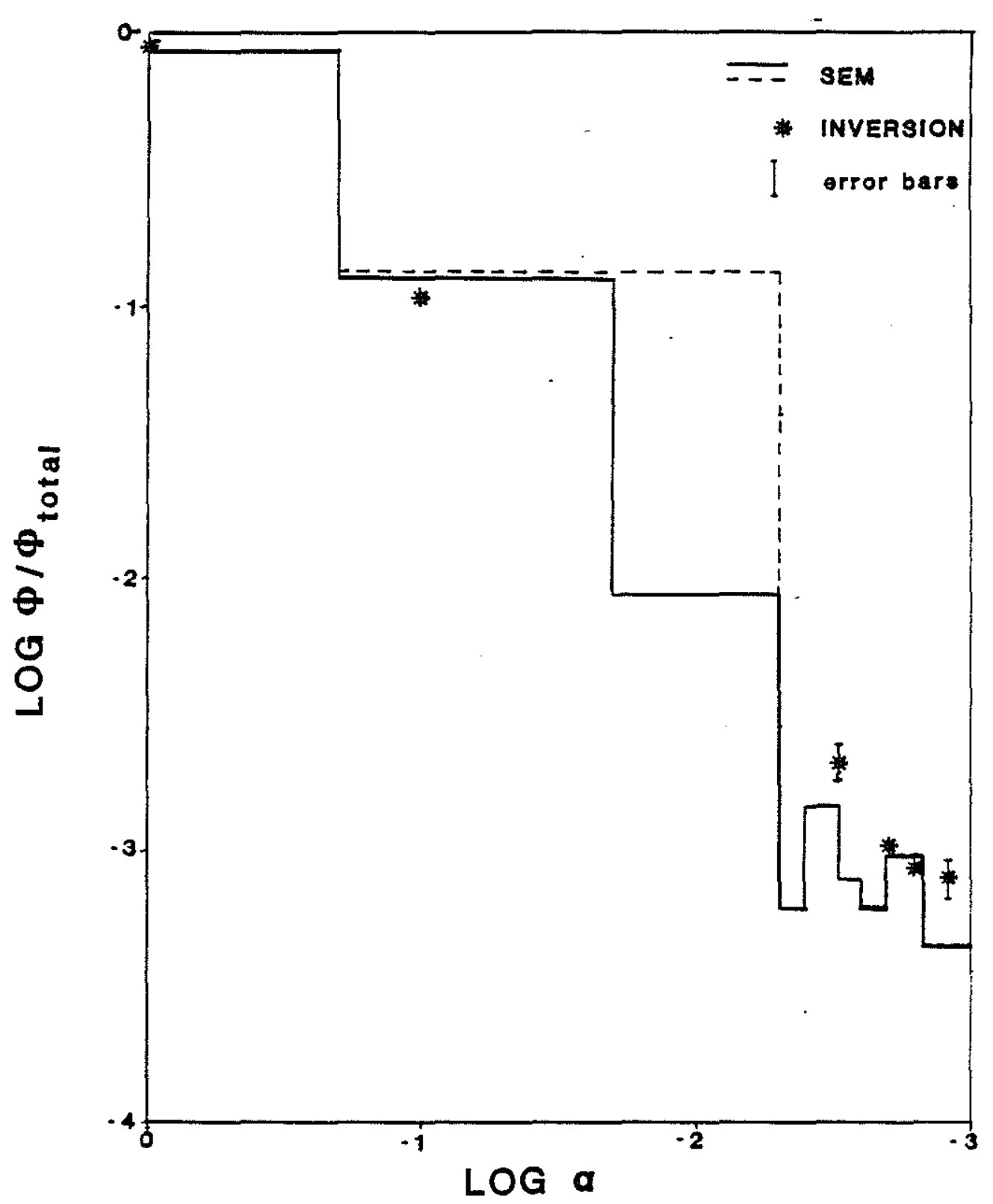

Figure 8b: Aspect ratio spectra from SEM measurements (histogram) and velocity inversion (stars)for the Navajo Sandstone. The SEM spectra is grouped such that all pore volume with aspect ratio less than or equal to the left edge value and greater than the right edge value is included in each bar. 


\section{Sandstone Pore Spectra}

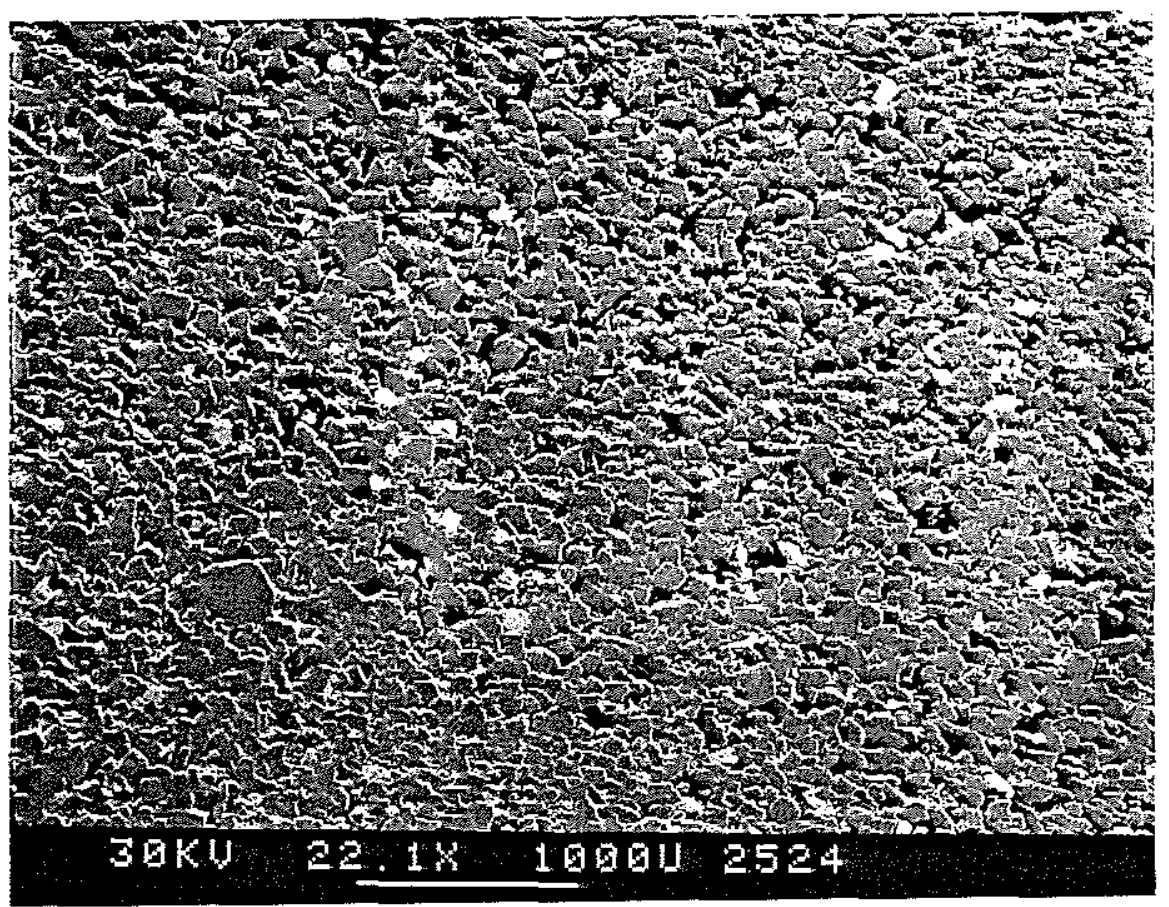

Figure 9: Low magnification image (22.1x) of the Weber Sandstone.

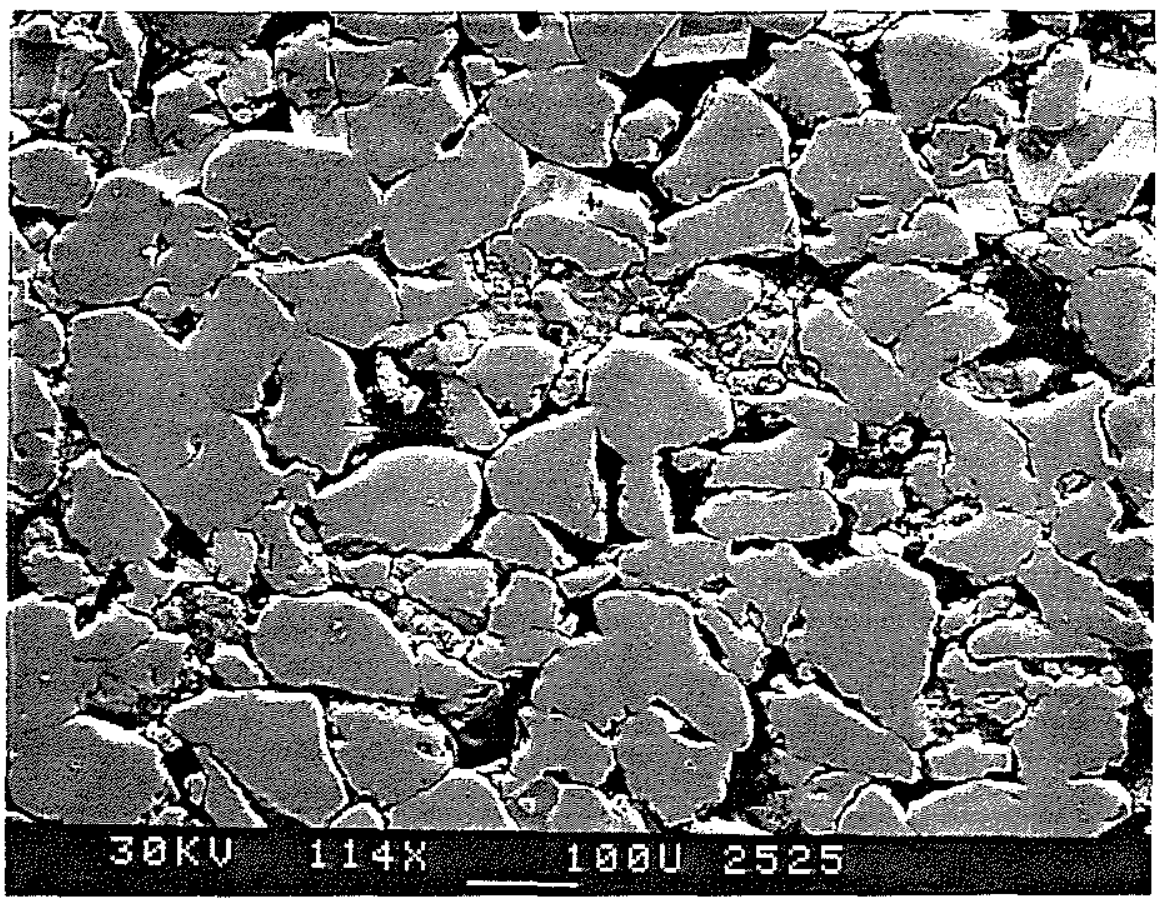

Figure 10: Primary image used in pore characterization of the Weber Sandstone $(114 \mathrm{x})$. 
Burns et al.

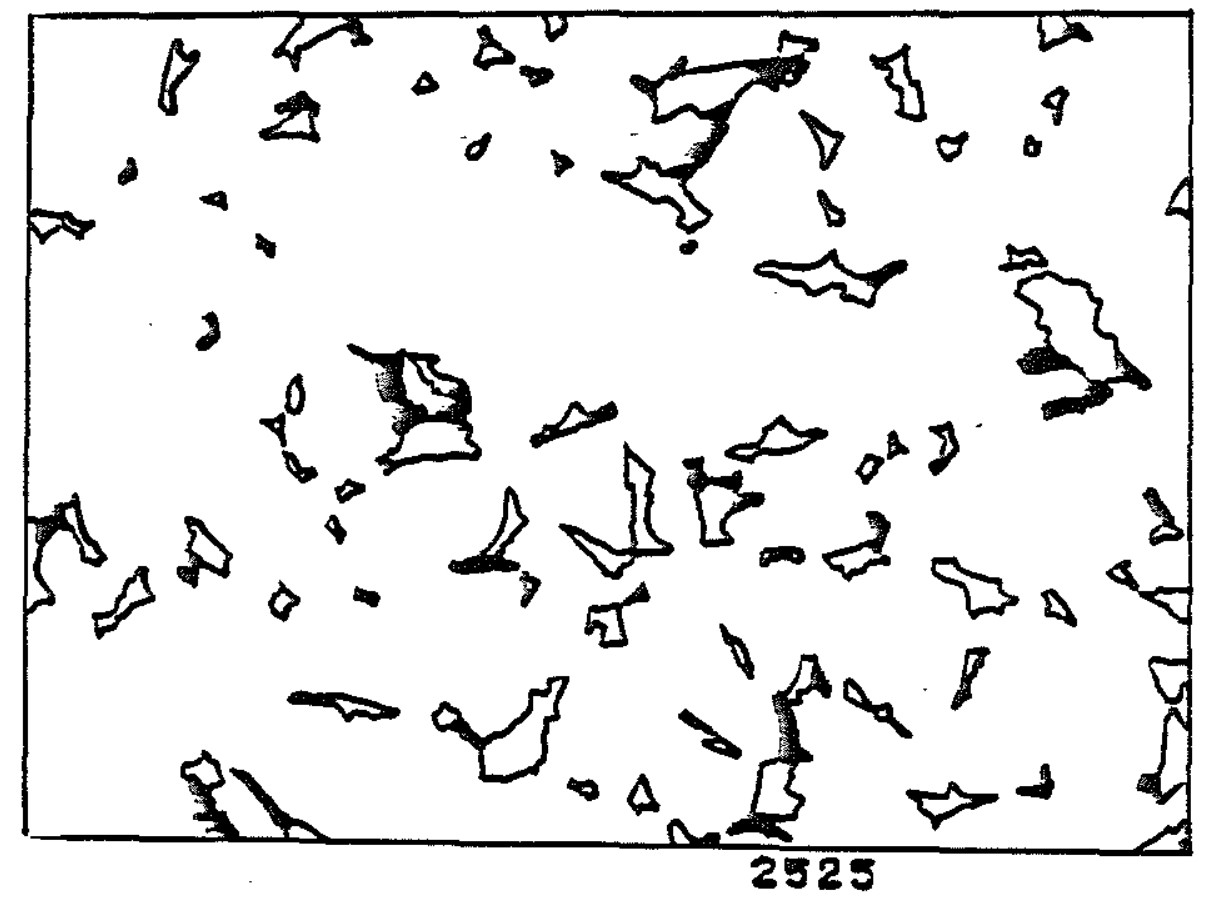

Figure 11: Intergranular (open) and intergranular/tabular (shaded) pores for the Weber Sandstone.

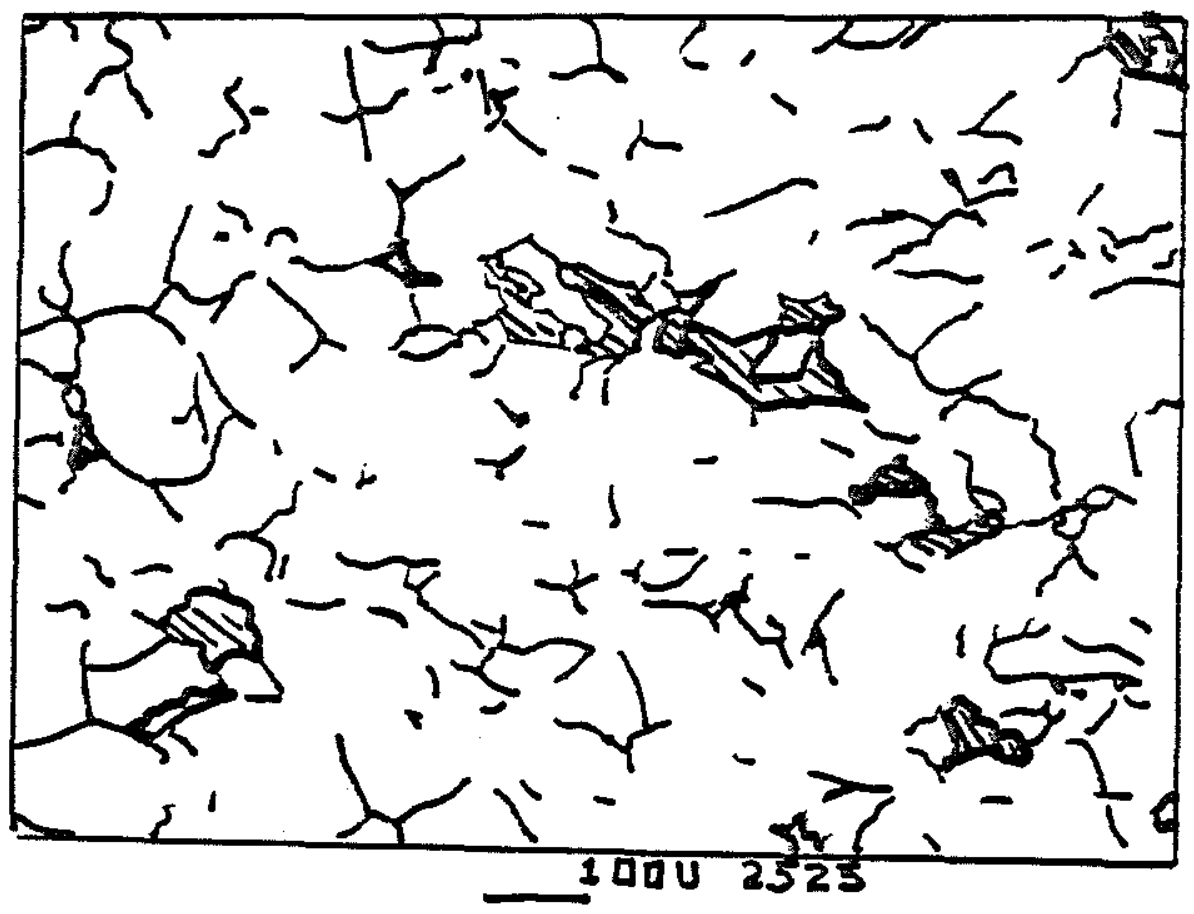

Figure 12: Connective (lines) and micro (shaded) pores for the Weber Sandstone. 


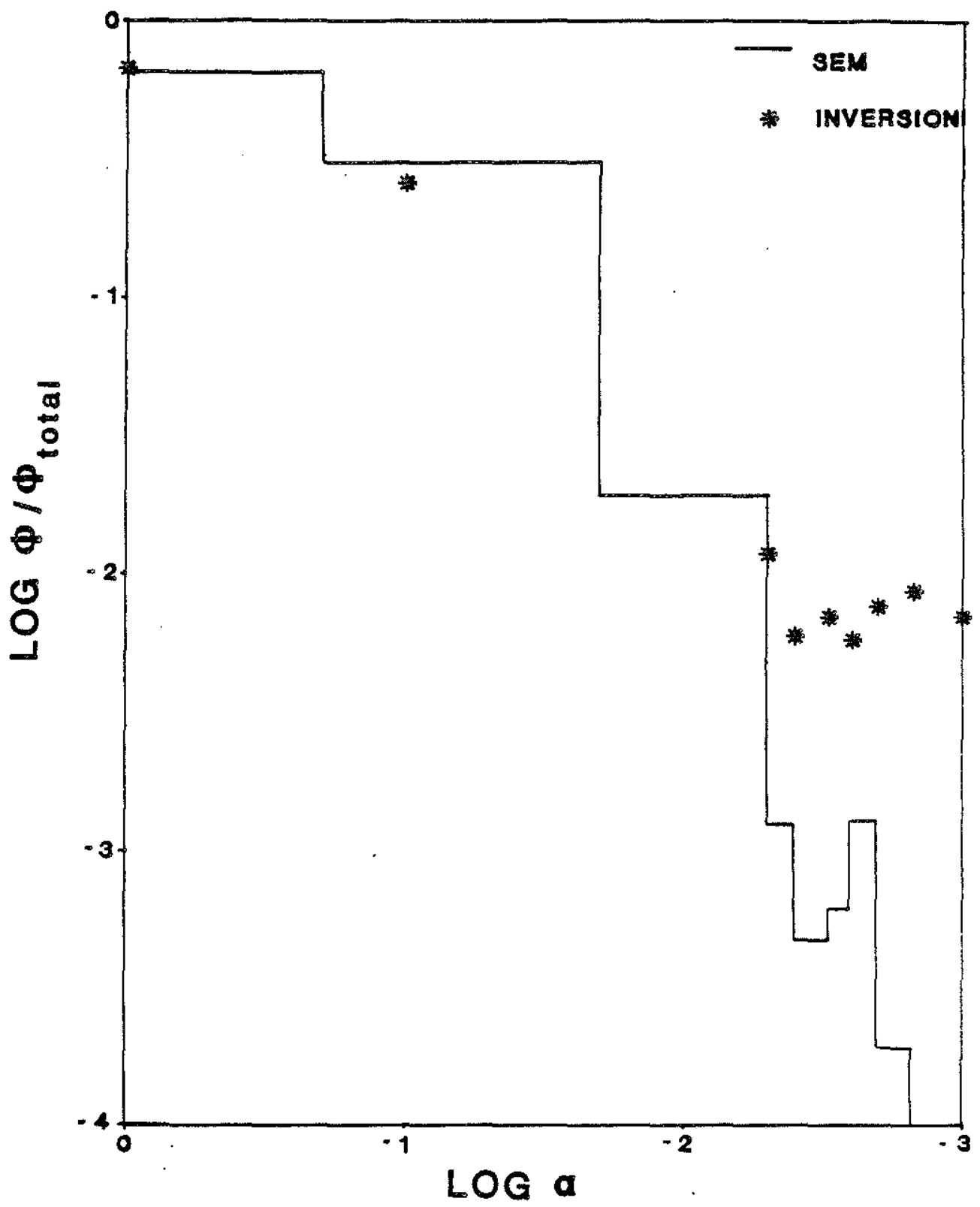

Figure 13: Aspect ratio spectra from the SEM (histogram) and the velocity inversion (stars) methods for the Weber Sandstone. 


\section{Burns et al.}

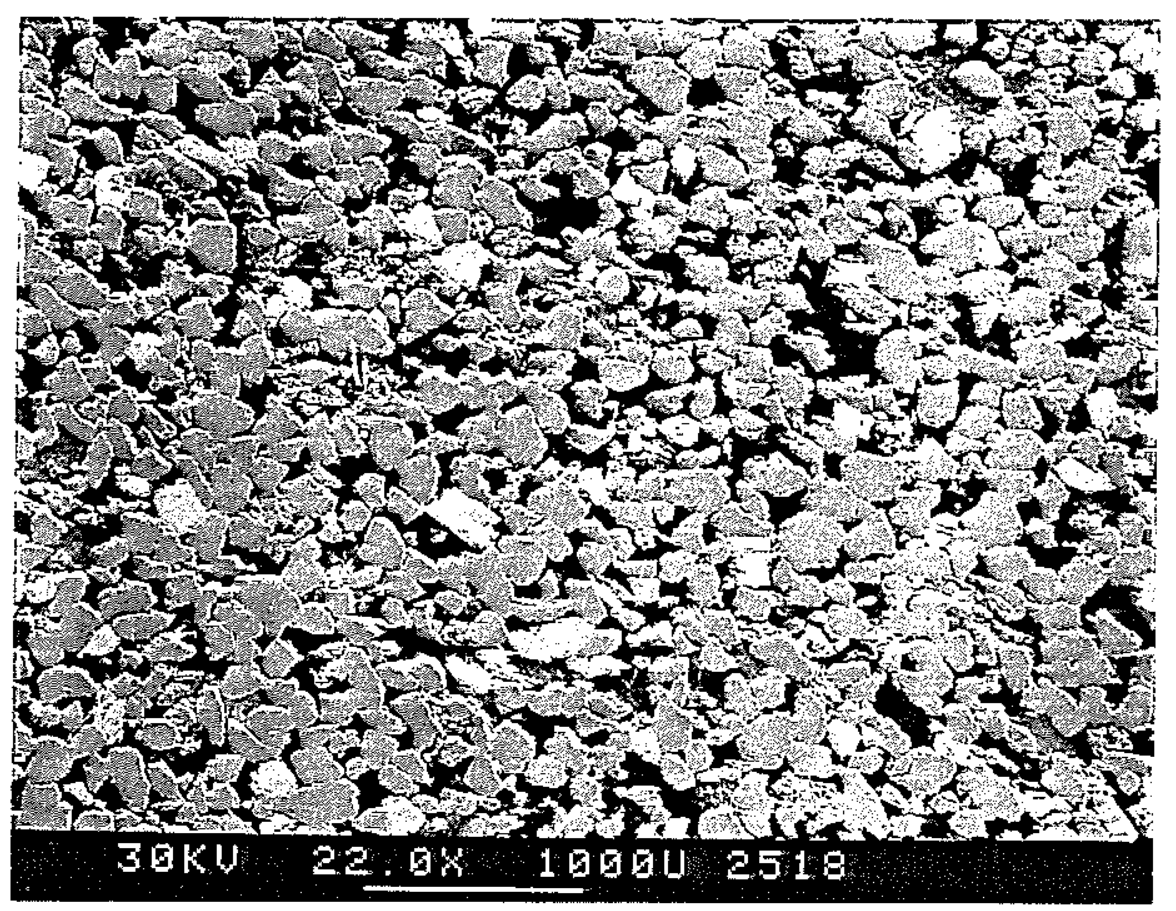

Figure 14: Low magnification image (22x) of the Kayenta Sandstone.

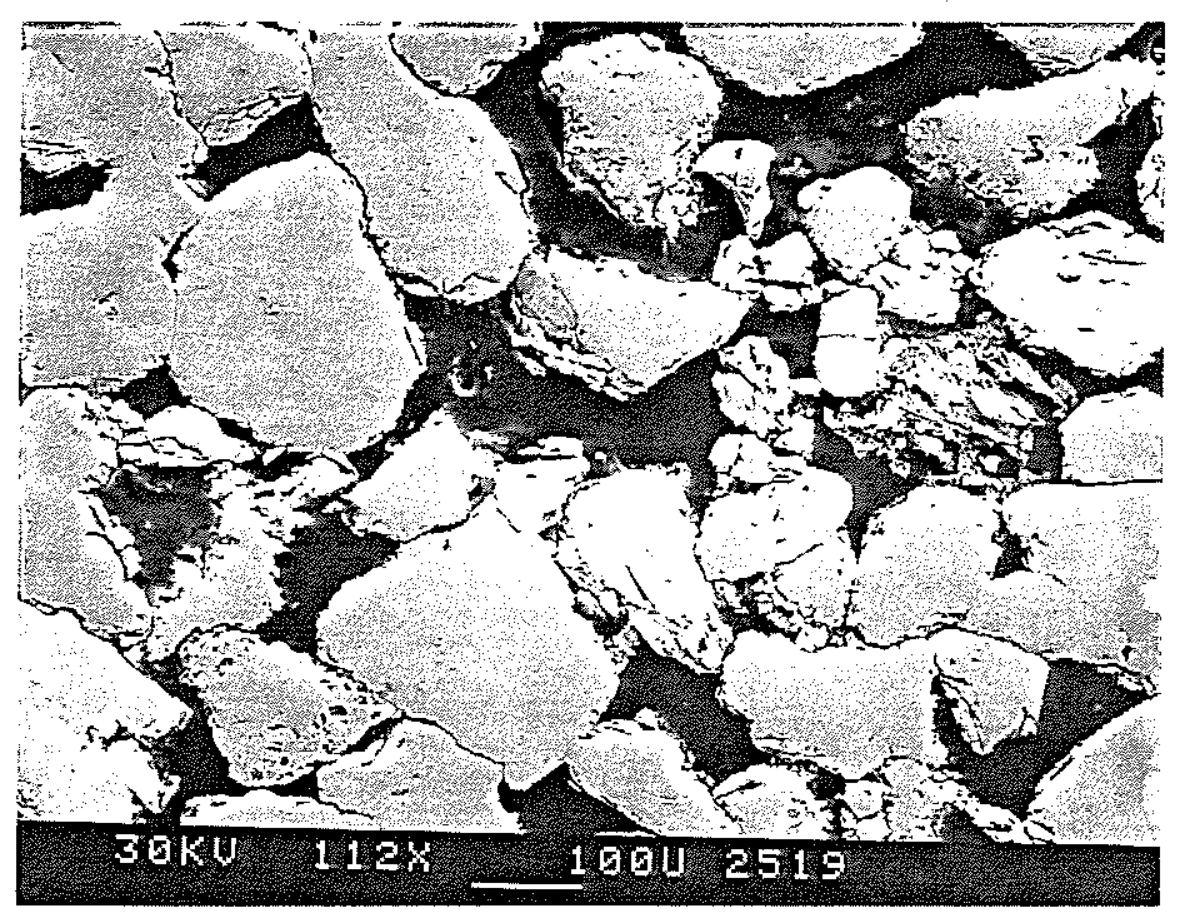

Figure 15: Primary image used in pore characterization of the Kayenta Sandstone (112x). 


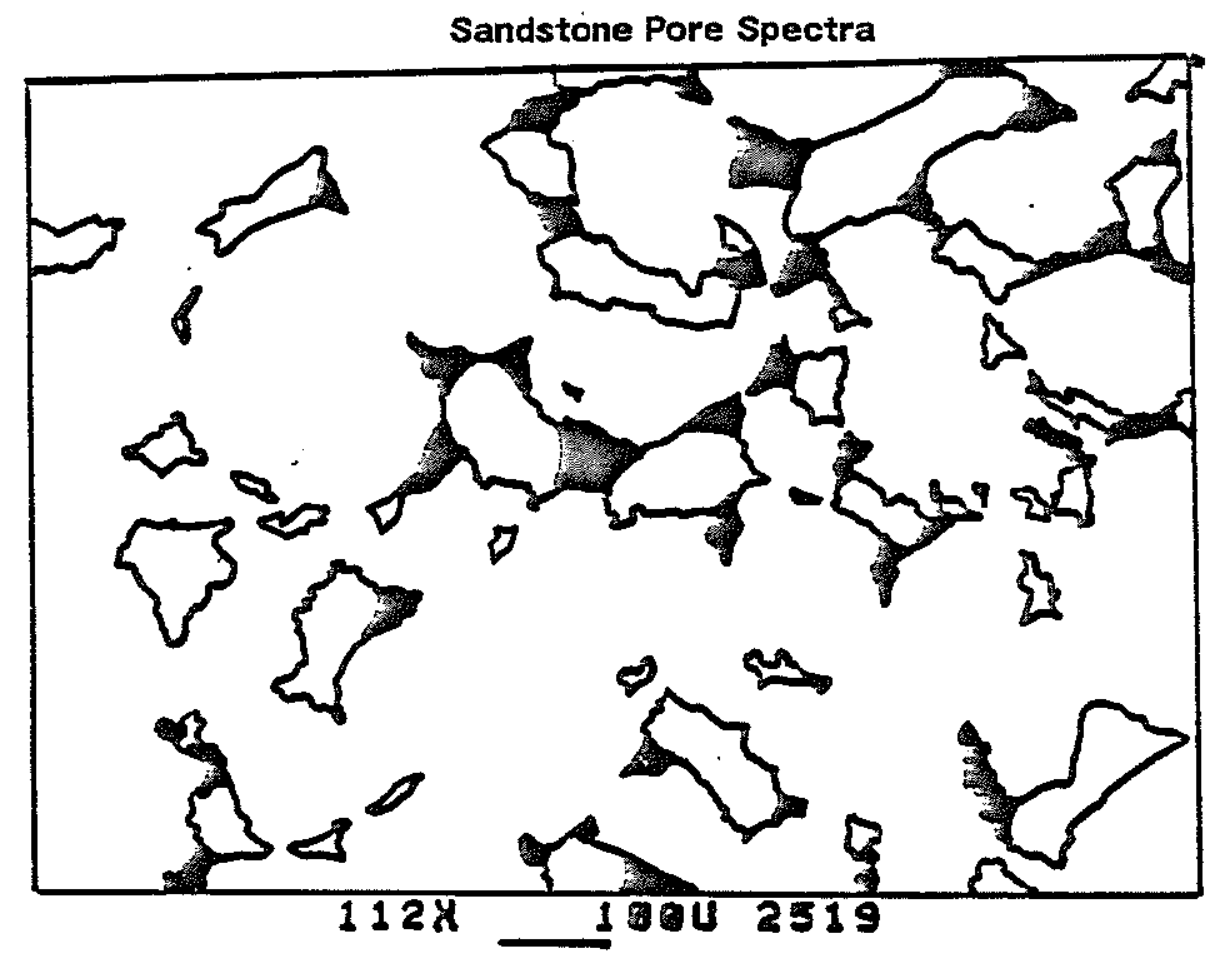

Figure 16: Intergranular (open) and intergranular/tabular (shaded) pores for the Kayenta Sandstone.

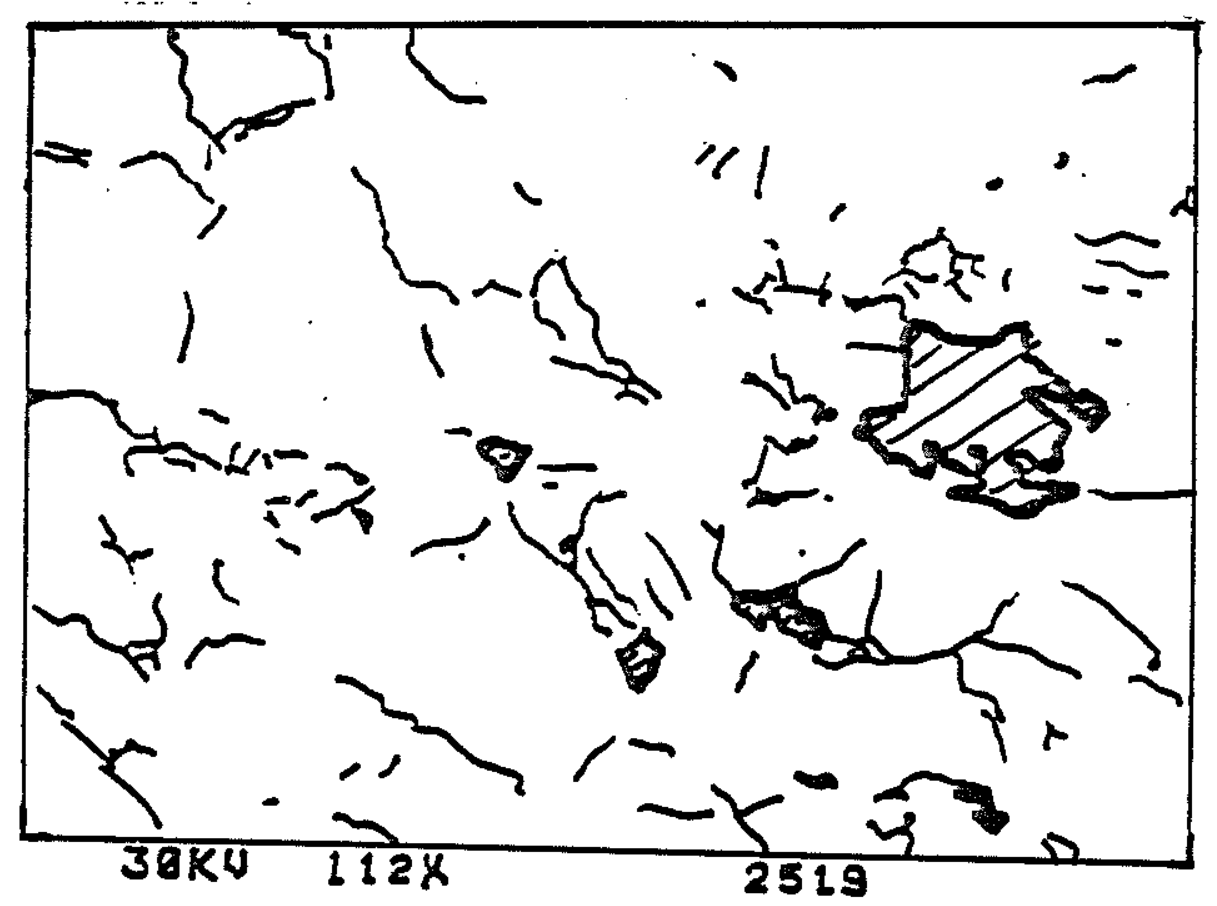

Figure 17: Connective (lines) and micro (shaded) pores for the Kayenta Sandstone. 


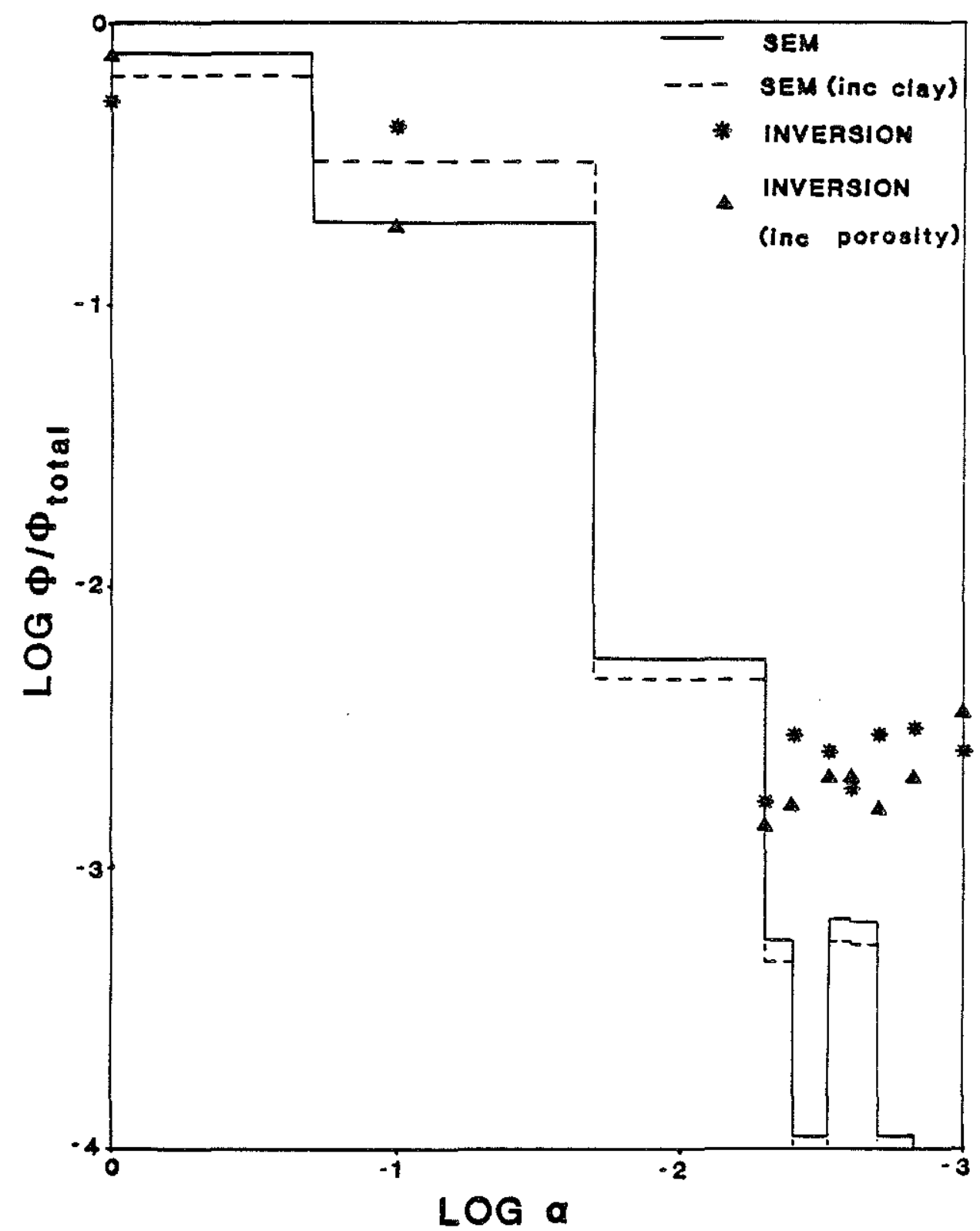

Figure 18: Aspect ratio spectra from the SEM (histogram) and the velocity inversion (symbols) methods for the Kayenta Sandstone. The solid line represents the measured SEM spectrum, while the dashed line represents the measured spectrum with a postulated clay content $3 \mathrm{x}$ that measured. The stars represent the velocity inversion results for the Kayenta Sandstone using the measured porosity of $22.2 \%$, while the triangles represent the inversion results using 27.2\% porosity to account for the non-void clay volume. 